\title{
Thermal and Structural Characterization of Transparent Rare-Earth Doped Lead Fluoride Glass-Ceramics
}

\author{
Chaouki Bensalem $^{1,2}$, Michel Mortier ${ }^{1 *}$, Daniel Vivien ${ }^{1}$, Patrick Gredin ${ }^{1}$, Gilles Patriarche ${ }^{3}$, \\ Madjid Diaf $^{2}$
}

${ }^{1}$ Laboratoire de Chimie de la Matière Condensée de Paris, UPMC, Chimie ParisTech, Paris, France; ${ }^{2}$ Département de Physique, Université d'Annaba, Annaba, Algérie; ${ }^{3}$ Laboratoire de Photonique et Nanostructures, Marcoussis, France.

Email: ${ }^{*}$ michel-mortier@chimie-paristech.fr

Received December $1^{\text {st }}, 2011$; revised January $9^{\text {th }}, 2012$; accepted January $22^{\text {nd }}, 2012$

\begin{abstract}
The devitrification of glasses with composition $50 \mathrm{GeO}_{2}-40 \mathrm{PbO}-10 \mathrm{PbF}_{2}-\mathrm{xREF}_{3}, \mathrm{RE}=\mathrm{Gd}, \mathrm{Eu}, 0<\mathrm{x} \leq 2$, leads to glass ceramics made of $\mathrm{RE}^{3+}: \beta-\mathrm{PbF}_{2}$ nanocrystals embedded in a glassy oxide matrix. This transformation is investigated using thermal analysis, X-ray diffraction and electron microscopy. A comparison with $\mathrm{RE}^{3+}: \beta-\mathrm{PbF}_{2}$ ceramics prepared by standard ceramic techniques is performed. The Rare Earth cations show a strong nucleating effect for the precipitation of the $\mathrm{RE}^{3+}: \beta-\mathrm{PbF}_{2}$ nanocrystals. The evolution of the unit cell parameters of the $\mathrm{REF}_{3}: \beta-\mathrm{PbF}_{2}$ solid solution results from a combined effect of $\mathrm{Pb}^{2+}-\mathrm{RE}^{3+}$ substitution and interstitial $\mathrm{F}^{-}$introduction. In the glass ceramics, $\mathrm{RE}^{3+}$ : $\beta-\mathrm{PbF}_{2}$ nanocrystals are constrained by the glassy matrix when they form with a pressure equivalent to $1.6 \mathrm{GPa}$. The constrained nanocrystals can return to a relaxed state by chemical dissolution of the embedding glassy matrix, followed by thermal treatments.
\end{abstract}

Keywords: Glass-Ceramic; Rare-Earth; Thermal Analysis; Devitrification; Nanocrystallite; X-Ray Diffraction

\section{Introduction}

Transparent oxyfluoride nano-glass-ceramics made photoluminescent by doping with Rare-Earth (RE) ions have been shown recently to be promising materials for new optical devices such as bulk laser media and amplifying laser fibers for optical communications [1-7]. These materials are easier to prepare than single crystals and can be made in a wide variety of shape and size. They are obtained by casting of a glass, using standard glass technology, followed by an appropriate heat treatment to generate the precipitation of fluoride nanocrystallites in the remaining oxide glass. Transparent glass-ceramics have interesting optical properties, since they exhibit narrower emission linewidths and higher emission crosssection than their parent glasses [4]. Therefore, they combine the processing ability of the glasses with the outstanding optical properties of the crystals.

For about ten years, we are engaged in the investigation of lanthanide-activated transparent oxyfluoride glassceramics prepared by annealing of glasses with typical composition $50 \mathrm{GeO}_{2}-40 \mathrm{PbO}-10 \mathrm{PbF}_{2}-\mathrm{xREF}_{3}$, in which the doping ions, which act as nucleating agents, are confined in $\beta-\mathrm{PbF}_{2}$ nanocrystals $[5,8-10]$.

*Corresponding author.
Recently, we have reported optical investigation of $\mathrm{EuF}_{3}$ doped lead fluorogermanate glasses [11], revealing that $\mathrm{Eu}^{3+}$ ions are not statistically distributed in the glass, but incorporated in fluorine rich islands separated by chains of $\mathrm{GeO}_{4}$ anions linked together. We have also compared the transparent glass-ceramic containing $\mathrm{Eu}^{3+}$ : $\beta-\mathrm{PbF}_{2}$ nanocrystallites obtained by devitrification of the above mentioned glass with the europium activated $\beta-\mathrm{PbF}_{2}$ ceramics [12]. It has been shown that their optical properties are almost identical and that, in these materials, europium ions are not isolated but engaged in dimers and higher nuclearity clusters. Furthermore, in co-doped $\mathrm{Gd}^{3+}$ : $\mathrm{Eu}^{3+}: \beta-\mathrm{PbF}_{2}$ ceramics, efficient energy transfer from $\mathrm{Gd}^{3+}$ to $\mathrm{Eu}^{3+}$ occurs [12]. This property might be used for instance for making photon-cutting phosphors for solar energy conversion and mercury-free fluorescent lamps $[13,14]$.

The present paper is devoted to the investigation of the transition between the glass and glass-ceramic in RE doped lead fluorogermanate glass, $\mathrm{RE}=\mathrm{Eu}$ or $\mathrm{Gd}$. It reports also the study of the lead fluoride nanoparticles of the glass-ceramic using both electron microscopy and Xray diffraction. It will be shown that these nanocrystals are constrained, with a unit cell parameter decrease that can reach about $1 \%$ with respect to this of the ceramic of 
the same composition.

\section{Experimental}

\subsection{Samplepreparation}

\subsubsection{Glass-Ceramics Containing $\mathrm{RE}^{3+}: \beta-\mathrm{PbF}_{2}$ Nanocrystallites}

A family of $\mathrm{REF}_{3}$-doped lead fluorogermanate glasses having the following compositions: $50 \mathrm{GeO}_{2}-40 \mathrm{PbO}-10$ $\mathrm{PbF}_{2}-\mathrm{xREF}_{3}, \mathrm{RE}=\mathrm{Gd}, \mathrm{Eu}, 0<\mathrm{x} \leq 2$ was prepared as described in a previous paper [11]. Then, the glasses were heated at $390^{\circ} \mathrm{C}$ for 10 hours, unless told otherwise. In the case of $\mathrm{Eu}^{3+}$, it has been shown that this devitrification process lead to a glass-ceramic made of $\mathrm{Eu}^{3+}: \beta$ $\mathrm{PbF}_{2}$ nanocrystals embedded in a glassy oxide matrix [11, 12,15-17]. Then, considering that lead fluoride amounts to $10 \%$ of the glasses composition, the glass-ceramics will be labelled GCRE10x $(\mathrm{RE}=\mathrm{Eu}$ or Gd), assuming a total segregation of the Rare-Earth in the $\mathrm{RE}^{3+}: \mathrm{PbF}_{2}$ nanocrystals. Consequently, the parent glasses will be referred to GRE10x. For the GCEu20 glass-ceramic, the $\mathrm{Eu}^{3+}: \beta-\mathrm{PbF}_{2}$ nanocrystallites were extracted from the glassy matrix by dissolving it in $10 \%$ hydrofluoric acid at room temperature for 7 hours [18]. The insoluble precipitate resulting from the chemical attack was separated by centrifugation, washed in distilled water and then dried in air.

\subsection{2. $\mathrm{RE}^{3+}: \boldsymbol{\beta}-\mathrm{PbF}_{2}$ Ceramics}

$\mathrm{RE}^{3+}: \beta-\mathrm{PbF}_{2}$ ceramics having the compositions $100 \mathrm{PbF}_{2}$, $\mathrm{y} \mathrm{REF}_{3}$, with $\mathrm{y}=5,10,15$ and 20 , and $\mathrm{RE}=\mathrm{Gd}$, Eu (hereafter labeled CREy) were prepared by crushing together, in an agate mortar, oven-dried commercial $\mathrm{PbF}_{2}$ and $\mathrm{REF}_{3}$ powders in appropriate amounts. The mixture was then heated at $550^{\circ} \mathrm{C}$ for 3 hours. It appeared essential to prevent the partial oxidation of $\mathrm{PbF}_{2}$ into lead oxyfluoride $\mathrm{Pb}_{2} \mathrm{OF}_{2}$ by conducting the heat treatment under a dry inert argon flow. X-ray diffraction was used to control that the as prepared CREy are single phased materials.

\subsection{Experimental Techniques}

Characteristic temperatures of the glasses, such as glass transition, crystallization onset and melting point, were determined from DTA (differential thermal analysis) curves obtained with a double symmetric analyzer TAG24 by Setaram. About $60 \mathrm{mg}$ of calibrated powder (particle size between 45 and $71 \mu \mathrm{m}$ ) of the sample were placed in an alumina crucible and compared to a burnt alumina neutral sample. The heating rate was $10^{\circ} \mathrm{C} / \mathrm{min}$.

The samples were studied by powder X-ray diffraction (XRD). The measurements were performed on a BRUKER AXS D5000 diffractometer equipped with a cobalt anode
$\left(\lambda_{\mathrm{K} \alpha}=1.789 \AA\right)$ for identification of the crystalline phases. To determine the unit cell parameters, the diffractometer was equipped with a copper anode and a secondary monochromator $\left(\lambda_{\mathrm{K} \alpha 1}=1.5406 \AA, \lambda_{\mathrm{K} \alpha 2}=1.5444 \AA\right)$. The zero shift of the goniometer was previously measured using a standard reference material $\left(\mathrm{Al}_{2} \mathrm{O}_{3}\right.$ from National Institute of Standards and Technology). The $2 \theta$ angular resolution was $0.02^{\circ}$. The diffraction patterns were scanned over the $2 \theta$ range $20^{\circ}-80^{\circ}$. X-ray powder patterns were firstly analyzed using the software EVA [19, 20]. The $\mathrm{K}_{\alpha 2}$ components of the diffraction lines were subtracted and the positions of diffraction peaks were then carefully measured in order to refine the cell parameters using the software CHECKCELL [21].

Transmission electron microscopy (TEM) and associated selected area electron diffraction (SAED) patterns were performed on a 200-kV Phillips CM20 microscope. The fine powder samples were placed onto a carboncoated copper grid. The microscope was equipped with an energy dispersive X-ray (EDX) analyzer which enables fluoride nanocrystals microanalysis with a detection limit of $0.1 \mathrm{at} \%$.

\section{Results}

\subsection{Crystallization of the Glass-Ceramics}

The DTA curves of the GGd10x glasses, as a function of $\mathrm{x}$, are given Figure 1. Starting from the low temperature side of the curves, one observes successively:

- The vitreous transition $\mathrm{T}_{\mathrm{g}}$, around $340^{\circ} \mathrm{C}$ for all the glasses.

- An exothermic peak labeled $\mathrm{T}_{\mathrm{c}}$ around $400^{\circ} \mathrm{C}$, associated with the crystallization of the Gadolinium-doped $\beta-\mathrm{PbF}_{2}$ phase. Its temperature decreases when the

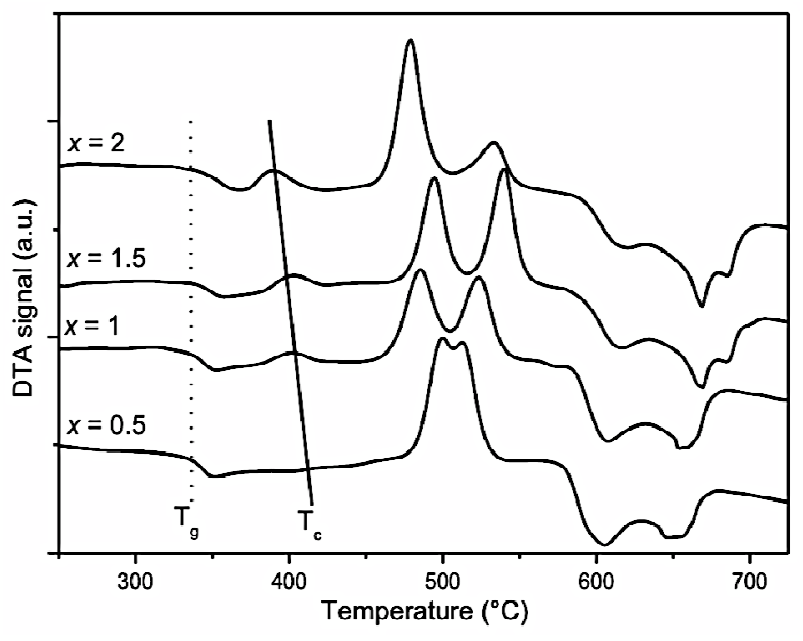

Figure 1. DTA curves of the GGd10x glasses. The dotted and solid lines indicate roughly the evolution of the glass transition temperature $T_{g}$ and the maximum of the $\mathrm{Gd}^{3+}$ : $\mathrm{PbF}_{2}$ crystallization peak $\mathrm{T}_{\mathrm{c}}$ respectively. 
$\mathrm{Gd}^{3+}$ doping rate increases.

- Several exothermic crystallization peaks between $460^{\circ} \mathrm{C}$ and $550^{\circ} \mathrm{C}$ that correspond to the formation of the mixed oxide phases $\mathrm{PbGeO}_{3}$ and $\mathrm{PbGe}_{4} \mathrm{O}_{9}$, as checked by XRD.

- Several endothermic peaks corresponding to the melting of the $\mathrm{Gd}^{3+}: \beta-\mathrm{PbF}_{2}$ and oxide phases above $550^{\circ} \mathrm{C}$.

These curves are quite similar to those obtained for the GEu10x series of glasses that have already been reported [11]. Nevertheless, it must be pointed out that, for a given $\mathrm{x}$ value, the $\mathrm{T}_{\mathrm{c}}\left(\mathrm{RE}: \beta-\mathrm{PbF}_{2}\right)$ is slightly shifted towards higher temperature for $\mathrm{RE}=\mathrm{Gd}$ compared to $\mathrm{Eu}$. For example for $\mathrm{x}=1.5, \mathrm{~T}_{\mathrm{c}}\left(\mathrm{Eu}: \beta-\mathrm{PbF}_{2}\right)=390^{\circ} \mathrm{C}$ and $\mathrm{T}_{\mathrm{c}}\left(\mathrm{Gd}: \beta-\mathrm{PbF}_{2}\right)=400^{\circ} \mathrm{C}$.

XRD can also be used to follow the crystallization rate of the glasses. As an example, Figure 2 reports the XRD of three glasses of the GCEu10x series obtained after annealing the parent glasses at $390^{\circ} \mathrm{C}$ for 10 hours. The narrow $\mathrm{Eu}^{3+}: \beta-\mathrm{PbF}_{2}$ (cubic, fluorite type) XRD peaks, are superimposed on broad bands centered around $2 \theta=$ $33^{\circ}$ and $55^{\circ}$ (for a cobalt anode) characteristic of the remaining amorphous oxide matrix.

It appears that the $\mathrm{Eu}^{3+}: \beta-\mathrm{PbF}_{2}$ Bragg peaks are very weak for $\mathrm{x}=0.5$, but rather strong for $\mathrm{x}=2$. To characterize the glass crystallization rate, one can separate the contributions of the RE: $\beta-\mathrm{PbF}_{2}$ peaks and of the glassy matrix by simulating the XRD trace as a sum of lorentzian lines and bands. Let us define the crystallization rate $R$ as the ratio between the sum of the intensities of the first four RE: $\beta-\mathrm{PbF}_{2}$ diffraction lines, over the area of the whole XRD trace shown in Figure 2.

The $\mathrm{R}$ values for GCRE10x glass-ceramics obtained at $390^{\circ} \mathrm{C}$ for 10 hours are reported Table 1. For GCGd20, the glassy oxide matrix begins to crystallize under such heat treatment. Therefore, for this sample, the annealing temperature was lowered to $385^{\circ} \mathrm{C}$ (Table 1).

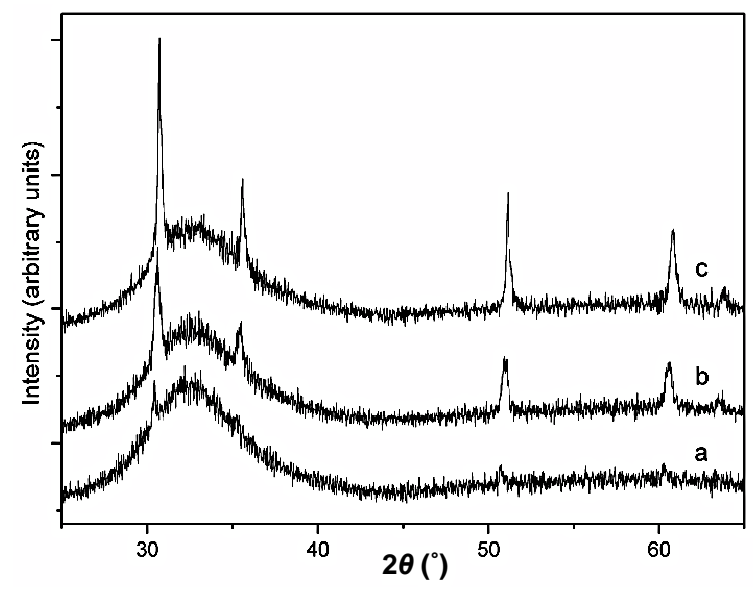

Figure 2. XRD patterns (cobalt anode) of three GEu10x glassceramics after annealing at $390^{\circ} \mathrm{C}$ for 10 hours: (a) $\mathrm{x}=0.5$; (b) $x=1.5$; (c) $x=2$.
Table 1. XRD $R$ values (see text) as a function of the RareEarth type and content $(x)$ in the GCRE10x glass-ceramics obtained by annealing of the parent glasses at $390^{\circ} \mathrm{C}$ for 10 hours.

\begin{tabular}{ccccc}
\hline x value & 0.5 & 1 & 1.5 & 2 \\
\hline$R(\%) \mathrm{RE}=\mathrm{Eu}$ & $3 \pm 2$ & $12 \pm 2$ & $12 \pm 2$ & $18 \pm 2$ \\
$R(\%) \mathrm{RE}=\mathrm{Gd}$ & $5 \pm 2$ & $13 \pm 2$ & $14 \pm 2$ & $14 \pm 2^{*}$ \\
\hline
\end{tabular}

${ }^{*}$ For this sample, the annealing temperature was set to $385^{\circ} \mathrm{C}$.

In the GCEu10x series, it can be observed that the highest $\mathrm{R}$ value, obtained for GCEu20, is $18 \% \pm 2 \%$ (Table 1). For this compound, $R$ remains constant either when increasing the annealing duration at $390^{\circ} \mathrm{C}$ or by increasing the annealing temperature to $400^{\circ} \mathrm{C}$. Therefore, it can be considered that $R=18 \% \pm 2 \%$ corresponds to the complete crystallization of the $\mathrm{Eu}^{3+}: \beta-\mathrm{PbF}_{2}$ phase in the glass-ceramics. Let us consider now the GCGd10x series. It must be noticed that $\mathrm{Eu}: \beta-\mathrm{PbF}_{2}$ and $\mathrm{Gd}: \beta-\mathrm{PbF}_{2}$ have very similar chemical composition, essentially made of $\mathrm{PbF}_{2}$, since their $\mathrm{RE} / \mathrm{Pb}$ ratio is at most equal to 0.2 . The mass attenuation coefficients of europium and gadolinium for the cobalt $\mathrm{K} \alpha \mathrm{X}$-ray wavelength are very close. Furthermore, these chemical elements are neighbors in the periodic table, and have very similar atomic diffusion factors. Then, the intensities of the XRD peaks of GCEu10x and GCGd10x are expected to be almost identical for a given crystallization rate. It follows that $\mathrm{R}$ values for GCEu10x and GCGd10x can be directly compared and the total crystallization for GCGd10x sample would correspond also to a $R$ value close to $18 \%$. Unfortunately, GCEU20 and GCGd20 samples cannot be compared easily because of different annealing temperatures.

\section{2. $R E: P F_{2}$ Nanoparticles Size and Shape in the Glass-Ceramics}

The crystallite sizes $L$ of the RE: $\mathrm{PbF}_{2}$ in the glass-ceramics can be extracted from the width at half maximum $\Delta(2 \theta)$ of the RE: $\mathrm{PbF}_{2}$ Bragg diffraction peaks according to the Scherrer formula

$$
\mathrm{L}=\frac{\lambda_{\mathrm{k} \alpha}}{\Delta(2 \theta) \cos (\theta)}
$$

in which $\lambda_{\mathrm{k} \alpha}$ is the $\mathrm{K} \alpha \mathrm{X}$-ray wavelength.

The $L$ values for the RE: $\mathrm{PbF}_{2}$ nanocrystals in the annealed GCRE10x glass-ceramics, averaged over the four first XRD peaks, are reported in Table 2.

The RE: $\mathrm{PbF}_{2}$ nanoparticles shape in the glass-ceramics has been studied using electron microscopy. Figure 3 shows the TEM images of two glass ceramics samples: GCGd15 (Figure 3(a)) and GCEu20 (Figure 3(b)).

\section{3. $\mathbf{R E}^{3+}: \mathrm{PbF}_{2}$ Unit Cell Parameters of the Glass-Ceramics and Ceramics}

The $\mathrm{RE}^{3+}: \beta-\mathrm{PbF}_{2}$ unit cell parameters $a$ of the CREy ce- 
ramics and GCRE10x glass-ceramics obtained after annealing of the parent glasses are gathered in Table 3 and shown in Figure 4. It has been shown previously that in the GCRE10x glass-ceramics, $a$ is independent of the crystallization rate $[22,23]$. The first nanocrystals that precipitate in a GRE10x glass have the same composition than the last ones, e.g. $10 x \mathrm{REF}_{3}-100 \mathrm{PbF}_{2}$. Generally

Table 2. $\mathrm{RE}^{3+}: \beta-\mathrm{PbF}_{2}$ crystallite sizes in the glass-ceramics obtained by annealing at $390^{\circ} \mathrm{C}$ for 10 hours, calculated from the linewidth of the $\mathrm{RE}^{3+}: \mathrm{PbF}_{2}$ Bragg diffraction peaks.

\begin{tabular}{ccccc}
\hline x Value & 0.5 & 1 & 1.5 & 2 \\
\hline$L(\mathrm{~nm}) \mathrm{RE}=\mathrm{Eu}$ & $52 \pm 4.8$ & $31 \pm 1.7$ & $28 \pm 1.4$ & $36 \pm 2.2$ \\
$L(\mathrm{~nm}) \mathrm{RE}=\mathrm{Gd}$ & $44 \pm 3.5$ & $22 \pm 1.7$ & $15 \pm 0.4$ & $14^{*} \pm 0.4$ \\
\hline
\end{tabular}

*The annealing temperature was $385^{\circ} \mathrm{C}$.
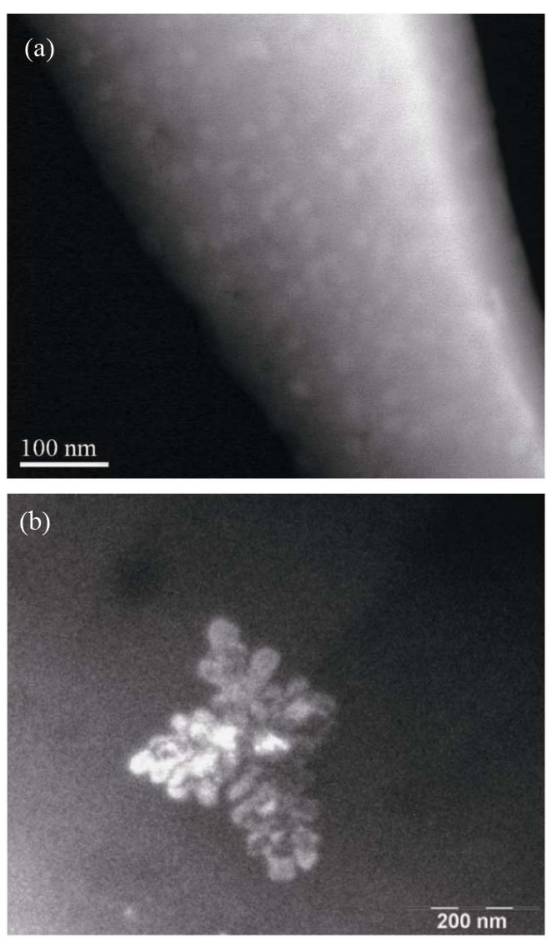

Figure 3. Transmission electron micrograph showing the $\mathrm{RE}: \boldsymbol{\beta}-\mathrm{PbF}_{2}$ nanoparticles embedded in the glassy matrix in: (a) GCGd15 glass-ceramic; (b) GCEu20 glass-ceramic (dark field image).

Table 3. Unit cell parameters $(\AA)$ of the $\mathrm{RE}^{3+}: \beta-\mathrm{PbF}_{2}$ phase in the CREy ceramics, and GCRE10x glass-ceramics obtained after annealing of the parent glasses at $390^{\circ} \mathrm{C}$ for 10 hours (e.s.d. are given in brackets).

\begin{tabular}{cccccc}
\hline $\mathrm{y}=10 \mathrm{x}$ & RE atomic \% & CGdy & CEuy & GCGd10x & GCEu10x \\
\hline 5 & 4.76 & $5.927(1)$ & $5.931(1)$ & $5.899(2)$ & $5.909(2)$ \\
10 & 9.09 & $5.915(1)$ & $5.920(2)$ & $5.874(2)$ & $5.889(2)$ \\
15 & 13.04 & $5.905(2)$ & $5.910(1)$ & $5.856(2)$ & $5.878(2)$ \\
20 & 16.67 & $5.895(1)$ & $5.904(1)$ & $5.836(2)$ & $5.868(2)$ \\
\hline
\end{tabular}

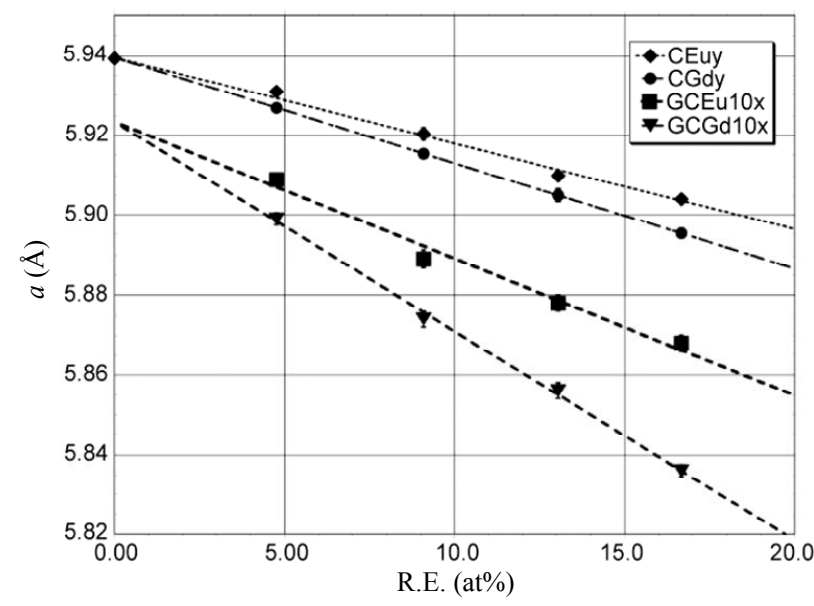

Figure 4. Variation of the unit cell parameter of the $\mathbf{R E}^{3+}$ : $\beta-\mathrm{PbF}_{2}$ phases in the ceramics CREy and glass-ceramics GCRE10x as a function of the Rare Earth atomic fraction $\left(\frac{100 \times y}{1+y}\right)$ in these phases for $R E=G d$ and $E u$.

speaking, the size of the RE: $\mathrm{PbF}_{2}$ unit cell is always smaller than the pure $\beta-\mathrm{PbF}_{2}$ one $(a=5.94 \AA)$ [24] and decreases when the RE content increases. In the CREy ceramics and the GCRE10x glass-ceramics, the variation of the unit cell parameter $a$, as function of their Rare Earth content, obeys the Vegard's law, e.g. it depends linearly on the RE atomic fraction. For a given RareEarth content, the unit cell parameter $a$ is always smaller for Gd than for Eu in the CREy series as well as in the GCRE10x one.

In the case of the ceramics, and for both $\mathrm{Gd}$ and $\mathrm{Eu}, a$ extrapolates for $\mathrm{y}=0$ to the pure $\beta-\mathrm{PbF}_{2}$ unit cell parameter value (Figure 4) as expected. However, for a given RE and a given doping rate, the unit cell parameter of the $\mathrm{RE}^{3+}: \mathrm{PbF}_{2}$ nanoparticles in the glass-ceramic is always significantly smaller than the unit cell parameter of the ceramic (Table 3). The lines of the Gd and $\mathrm{Eu}$ glass-ceramics (Figure 4) extrapolate for $\mathrm{x}=0$ to $a=$ $5.924 \AA$.

\subsection{Investigation of the Eu: $\mathrm{PbF}_{2}$ Nanoparticles Extracted from the GCEu20 Sample}

The XRD of the insoluble mixture obtained after HF attack of the GCEu20 glass-ceramic, as described above, is shown in the Figure 5(a). For sake of comparison, the XRD of the GCEu20 sample prior to the chemical attack and of the CEu20 ceramic are also given Figures 5(d) and (c) respectively.

Under chemical treatment of the glass-ceramic with $\mathrm{HF}$, the $\left(50 \mathrm{GeO}_{2}-40 \mathrm{PbO}\right)$ glassy matrix transforms into soluble $\mathrm{GeF}_{4}$ and insoluble $\alpha-\mathrm{PbF}_{2}$. Since the $\mathrm{Eu}^{3+}$ : $\beta-\mathrm{PbF}_{2}$ nanoparticles extracted from the glass are also insoluble, one obtains a mixture, the two component of 
which are easily distinguished using transmission electron microscopy imaging as shown in Figure 6. The $\alpha$ $\mathrm{PbF}_{2}$ crystals appear as needles $\sim 2 \mu \mathrm{m}$ long and $\sim 200 \mathrm{~nm}$ in diameter. They are surrounded by the $\mathrm{Eu}^{3+}: \beta-\mathrm{PbF}_{2}$ nanocrystallites, which are much smaller and often agglomerated into dendrimers shaped nanoparticles typically $100 \mathrm{~nm}$ in size. The chemical composition of the two kinds of lead fluoride was established using EDX microanalysis. The $\mathrm{Eu}^{3+}: \beta-\mathrm{PbF}_{2}$ composition, averaged over several nanocrystallites, is (in atomic \%): $\mathrm{Pb}: 24.9$, $\mathrm{Eu}: 5.6, \mathrm{~F}: 69.5$.

The large $\alpha-\mathrm{PbF}_{2}$ needles are surrounded by smaller Eu doped $\beta-\mathrm{PbF}_{2}$ nanoparticles. Since the glass-ceramic contains $40 \mathrm{PbO}$, which transform into $40 \alpha-\mathrm{PbF}_{2}$ upon $\mathrm{HF}$ attack and $10 \mathrm{Eu}^{3+}: \beta-\mathrm{PbF}_{2}$, the $\alpha-\mathrm{PbF}_{2}$ dominate in the XRD of the insoluble mixture (Figure 5(a)). The $\mathrm{Eu}^{3+}: \beta-\mathrm{PbF}_{2} \mathrm{XRD}$ peaks, which are at the same diffraction angles than in the parent glass-ceramic GCEu20 (Figure 5(d)) have been marked with arrows in Figure

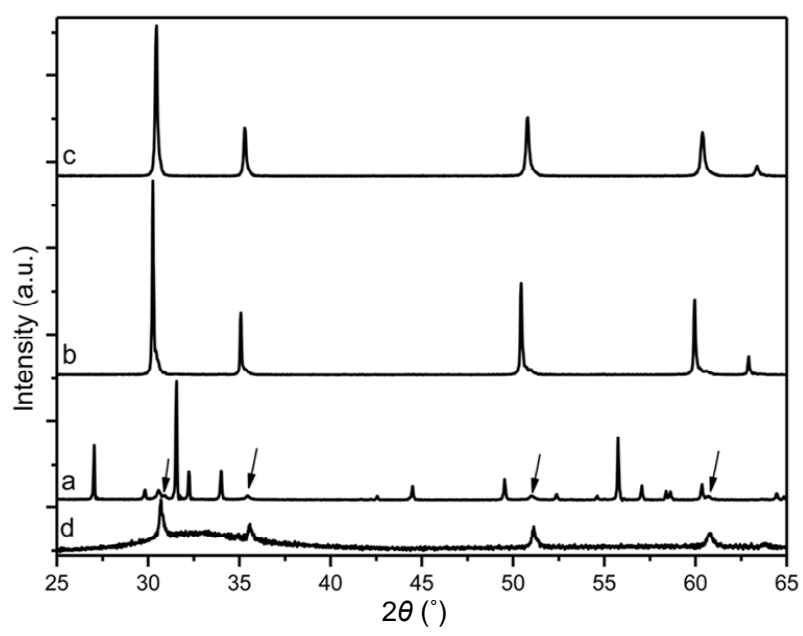

Figure 5. XRD patterns (cobalt anode) of the mixture resulting from the HF attack of GCEu20 glass-ceramic. (a) as obtained after drying, (b) after annealing at $400^{\circ} \mathrm{C}$ for 3 hours under argon atmosphere. The XRD patterns of CEu20 ceramic (c) and GCEu20 prior to HF attack (d) are given for comparison. The arrows on trace (a) indicate the XRD peaks of the $\mathrm{Eu}^{3+}: \beta-\mathrm{PbF}_{2}$ nanocrystallites which are at the same position than those of trace $(d)$.

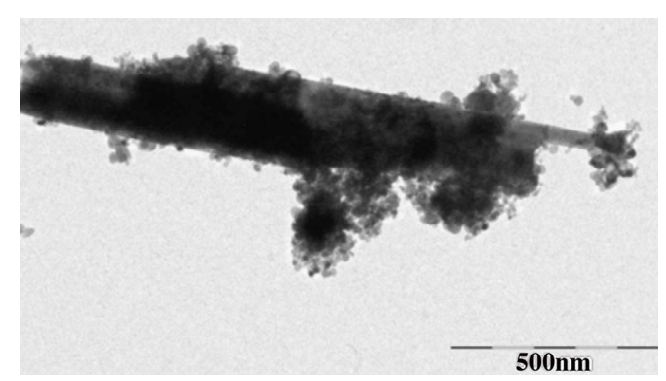

Figure 6. TEM image of the mixture resulting from HF attack of the GCEu20 glass ceramic. 5(a), in order to facilitate their identification.

Figure 5(b) exhibits the XRD pattern of the above mixture after annealing for 3 hours at $400^{\circ} \mathrm{C}$ under argon atmosphere in order to prevent the lead fluoride oxidation. Under such conditions, metastable $\alpha-\mathrm{PbF}_{2}$ transforms into undoped $\beta-\mathrm{PbF}_{2}$. The $\mathrm{Eu}^{3+}: \beta-\mathrm{PbF}_{2}$ nanocrystallites manifest themselves as a shoulder on the large angle side of each undoped $\beta-\mathrm{PbF}_{2}$ peak, which dominate the XRD diagram. Figure 7 presents, as an example, an expanded view of the XRD diagram shown in Figure 5(b), around $2 \theta=51^{\circ}$ (cobalt anode) corresponding to the $\beta-\mathrm{PbF}_{2}$ (311) peak region. The observed trace can be fitted as a sum of three lorentzian peaks labeled A, B and $\mathrm{C}$ in Figure 7.

\section{Discussion}

\subsection{Nucleating Efficiencies of the RE Dopants in the Glass-Ceramics}

The nucleating character of the Rare-Earth ions in the $\mathrm{REF}_{3}$-doped lead fluorogermanate or fluorosilicate glasses is well documented $[4,6-8,11]$. Here, the $\mathrm{Eu}^{3+}$ and $\mathrm{Gd}^{3+}$ nucleating role is evidenced by the decrease of the $\beta-\mathrm{PbF}_{2}$ crystallization temperature when the Rare-Earth content of the glasses increases as shown in Figure 1. Evolution of the XRD patterns (Figure 2) and crystallization rate $R$ (Table 1) of the GCRE10x glass-ceramics, as a function of the $\mathrm{RE}$ doping rate, confirms that $\mathrm{RE}^{3+}$ ions promote the crystallization of the lead fluoride nanocrystals. Assuming that the crystallization rate $R$ of the glass GREy varies linearly with the amount of $\mathrm{RE}^{3+}: \beta-\mathrm{PbF}_{2}$ nanocrystals formed, one can deduce that there are only about $1 / 4$ of the total $\mathrm{PbF}_{2}$ content of the glass that form $\mathrm{RE}^{3+}: \beta$

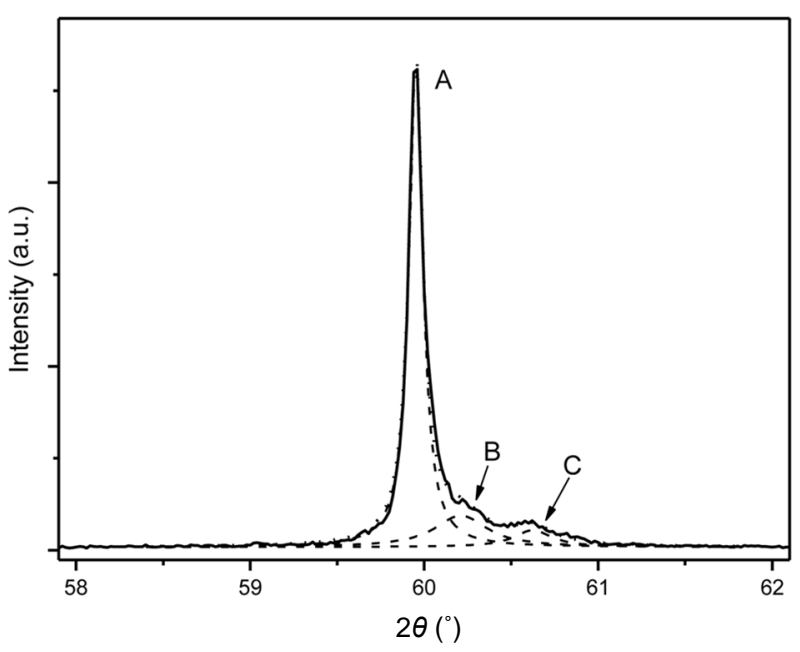

Figure 7. Expanded view of the (311) XRD peak (cobalt anode) of the insoluble mixture resulting from the HF attack of the GCEu20 ceramic after annealing for 3 hours at $400^{\circ} \mathrm{C}$. The observed peak can be deconvoluted into three lorentzian peaks labeled $A, B$ and $C$. 
$\mathrm{PbF}_{2}$ nanocrystals for GCRE5 and 2/3 for GCRE10 (Table 1).

The present results allow comparing the nucleating efficiencies of $\mathrm{GdF}_{3}$ and $\mathrm{EuF}_{3}$. Since the $\mathrm{PbF}_{2}$ crystallization peaks are at slightly lower temperatures for Eu than for $\mathrm{Gd}$, for a given Rare-Earth content, one can infer that in the GRE10x glass, europium has a slightly better $\beta$ $\mathrm{PbF}_{2}$ nucleating efficiency than gadolinium.

In previous works dealing with similar glasses doped with $\mathrm{CeF}_{3}, \mathrm{ErF}_{3}$ and $\mathrm{YbF}_{3}[8,25]$, it was shown that the $\mathrm{RE}: \beta-\mathrm{PbF}_{2}$ nucleation efficiency order of the Rare-Earth was $\mathrm{Ce}>\mathrm{Er}>\mathrm{Yb}$. Table 4 gives the ionic radii, according to [26], of $\mathrm{Pb}^{2+}$ and several $\mathrm{RE}^{3+}$ ions in eightfold coordination and also crystallization temperatures of GRE10x glasses for $\mathrm{x}=1.5$ and $\mathrm{x}=2$. It appears that the bigger is the Rare-Earth cation, the higher is its lead fluoride nucleating power in the glass. Indeed, for a given $\mathrm{REF}_{3}$ content (10x) of the GRE10x glasses, the crystallization temperature increases when the R.E. ion size decreases (Table 4). It means that the efficiency of the Rare-Earth ion to promote the precipitation of $\mathrm{RE}^{3+}: \beta-\mathrm{PbF}_{2}$ nanocrystallites increases with the R.E. ion size. This may be related to the stability of the RE: $\beta-\mathrm{PbF}_{2}$ fluorite solid solution, whose solubility limit, and consequently thermodynamic stability, decreases when the RE ionic radius decreases [24], e.g. when the size difference with respect to $\mathrm{Pb}^{2+}$ increases. It is more difficult to deduce the relative nucleating efficiencies of Eu and Gd using the crystallization rates $\mathrm{R}$ (Table 1). The $\mathrm{R}$ values for GCRE10x glass-ceramics (R.E.: Eu and Gd) for a given R.E. content are almost the same taking into account the standard errors.

\subsection{Size and Morphology of the $\mathrm{RE}^{3+}: \beta-\mathrm{PbF}_{2}$ Nanoparticles in the Glass-Ceramics}

In the GCGd10x series, the $\mathrm{Gd}^{3+}: \beta-\mathrm{PbF}_{2}$ nanoparticles are rather spherical and rather monodisperse as exemplified Figure 3(a) for the GCGd15 glass-ceramic. The nanoparticles diameter is about $18 \mathrm{~nm}$, in good agreement with the crystallite size of $15 \mathrm{~nm}$ deduce from the XRD linewidth (Table 2). Thus, the nanoparticle sizes can be

Table 4. Ionic radii (eightfold coordination) of lead and some Rare-Earth cations according to [26] and crystallization temperatures $\left(T_{c}\right)$ for $x=1.5$ and $x=2$ (this work for $\mathrm{Eu}^{3+}$ and $\mathrm{Gd}^{3+}$ and ref $[8,25]$ for the other rare earths) $N$.A.: not available because the crystallization peak is masked by another phenomenon, $<\mathrm{T}_{\mathrm{g}}$ : crystallization occurs at a temperature lower than the glass transition one.

\begin{tabular}{ccccccc}
\hline Ion & $\mathrm{Pb}^{2+}$ & $\mathrm{Ce}^{3+}$ & $\mathrm{Eu}^{3+}$ & $\mathrm{Gd}^{3+}$ & $\mathrm{Er}^{3+}$ & $\mathrm{Yb}^{3+}$ \\
\hline Ionic radius $(\AA)$ & 1.43 & 1.283 & 1.206 & 1.193 & 1.144 & 1.125 \\
$\mathrm{~T}_{\mathrm{c}}$ for $\mathrm{x}=1.5\left({ }^{\circ} \mathrm{C}\right)$ & - & $<\mathrm{T}_{\mathrm{g}}$ & 383 & 401 & N.A. & 434 \\
$\mathrm{~T}_{\mathrm{c}}$ for $\mathrm{x}=2\left({ }^{\circ} \mathrm{C}\right)$ & - & $<\mathrm{T}_{\mathrm{g}}$ & N.A. & 391 & 423 & 427 \\
\hline
\end{tabular}

assimilated with the nanocrystallites ones obtained from $\mathrm{XRD}$. The $\mathrm{Gd}^{3+}: \beta-\mathrm{PbF}_{2}$ nanoparticle sizes decrease when the RE content of the glass increases (Table 2). This observation is in agreement with the increase of the nucleating efficiency with the R.E. content described in the previous part. This is easily understood when considering that higher is the RE content of the starting glass, the larger is the number of crystallization seeds, which therefore have no surrounding matter let to grow. Consequently, the nanocrystals are smaller.

On the contrary, the shape of the $\mathrm{Eu}^{3+}: \beta-\mathrm{PbF}_{2}$ nanoparticles of the GCEu10x series appears dendritic and not spherical, as shown in Figure 3(b) for the GCEu20 material. Consequently, the crystallite sizes obtained from XRD (Table 2) differ from the nanoparticles size for the europium doped glass-ceramic. Dentritic nanoparticles seem clearly constituted of several crystallites. Thus, it is difficult to correlate safely the evolution of the crystallite sizes with the nucleating efficiency as function of the R.E. content or as function of the R.E. element.

\subsection{Influence of the RE Content and Nature on the $\mathrm{RE}^{3+}: \boldsymbol{\beta}-\mathrm{PbF}_{2}$ Unit Cell Parameters}

We will first consider the decrease of the unit cell parameter of the CREy ceramics when their $\mathrm{REF}_{3}$ content $\mathrm{y}$ increases as reported in Figure 4 and Table 3. This decrease, for various RE cations, has already been noticed in previous studies for the ceramics [24,27] and also for glass-ceramics $[8,23]$, but the reasons for that were not fully discussed to our knowledge.

This decrease can be explained basically on the basis of sterical effects as follows. The $\mathrm{RE}^{3+}: \beta-\mathrm{PbF}_{2}$ ceramics have the cubic fluorite structure which can be described as a packing of fluoride cubes of $a / 2$ edge, the centre of which are alternatively empty and occupied by the $\mathrm{Pb}^{2+}$ cations. The CREy ceramics have the composition of points of the solid solution $\mathrm{PbF}_{2}-\mathrm{REF}_{3}$, which can be formulated $\mathrm{Pb}_{1-\mathrm{z}} \mathrm{RE}_{\mathrm{z}} \mathrm{F}_{2+\mathrm{z}}$ where $\mathrm{z}$, the atomic fraction, is expressed as $\mathrm{z}=\frac{\mathrm{y}}{1+\mathrm{y}}$. An approximate structural description of the $\mathrm{Pb}_{1-\mathrm{z}} \mathrm{RE}_{\mathrm{Z}} \mathrm{F}_{2+\mathrm{z}}$ compounds is to consider that $\mathrm{z} \mathrm{Pb}^{2+}$ are replaced by $\mathrm{z} \mathrm{RE}^{3+}$ cations, while simultaneously, $z$ interstitial fluoride ions takes place in the empty cubes of the structure and a part of fluoride ions migrate from normal positions to interstitial ones [24]. The $\mathrm{F}^{-}$ionic radius is taken equal to the greatest value $\sim 1.19 \AA$ and the $\mathrm{RE}^{3+}$ cations ionic radii (in eightfold coordination) are given in Table 4 . Let us first consider that the interstitial fluorides do not significantly affect the unit cell parameter of CREy. It seems reasonable since the fluoride cube in which they lie is large enough to geometrically accommodate them. Indeed, assuming that the interstitial $\mathrm{F}^{-}$is in the centre of the cube, the 
closest distance between fluoride ions occurs on the cube diagonal. For CRE20 for instance, $a \sim 5.90 \AA$ and

$$
\frac{a \sqrt{3}}{2}=5.11 \AA \text { is larger than } 4 \mathrm{r}\left(\mathrm{F}^{-}\right)=4.76 \AA \text {. }
$$

On the contrary the replacement of $\mathrm{Pb}^{2+}$ by smaller $\mathrm{RE}^{3+}$ ions will decrease the cation-anion distance in the substituted cubes and therefore the unit cell parameter. The higher is the RE content of the CREy, the smaller will be the $a$ parameter value. Furthermore, for a given RE content, since $\mathrm{r}\left(\mathrm{Gd}^{3+}\right)$ is slightly smaller than $\mathrm{r}\left(\mathrm{Eu}^{3+}\right)$, the solid solution unit cell parameter will be smaller for $\mathrm{RE}=\mathrm{Gd}$, than for $\mathrm{RE}=\mathrm{Eu}$. This is exactly what is observed in Figure 4.

On a more quantitative point of view, taking the ionic radii given Table 4 and assuming that $\mathrm{F}^{-}$and $\mathrm{RE}^{3+}$ touch each other along the diagonal of the $a / 2$ edge cube, one must estimate the unit cell parameter of a hypothetic fluorite crystal in which all $\mathrm{Pb}^{2+}$ ions would have been replaced by $\mathrm{RE}^{3+}$. This gives 5.53 and $5.50 \AA$ for $\mathrm{Eu}^{3+}$ and $\mathrm{Gd}^{3+}$ respectively. Then, for instance for the CRE20 solid solutions, in which the RE atomic fraction is $16.67 \%$, one expect a unit cell parameter to be the weight averaged unit cell of $\beta-\mathrm{PbF}_{2}$ and of the above hypothetic RE fluorites. This gives 5.872 for CEu20 and 5.866 for CGd20, in reasonable agreement with the experimental values, 5.904 and 5.895 respectively (Table 3 ). The difference between calculated and experimental values may be due to the effect of the interstitial fluorides, which tend to expand the cubes in which they lie, because of electrostatic repulsion between the interstitial $\mathrm{F}^{-}$and those occupying the vertices of the cubes. The same arguments hold for the evolution (Figure 4 and Table 3) of the $\mathrm{RE}^{3+}: \beta-\mathrm{PbF}_{2}$ unit cell parameter in the GCRE10x glassceramics, as function of the RE content $\mathrm{x}$ and of the RE type.

\subsection{Comparison of the Unit Cell Parameters of the $\mathrm{RE}^{3+}: \beta-\mathrm{PbF}_{2}$ Ceramics and Nanoparticles}

It must now be discussed why, for a given RE ion and a given doping rate, the $a$ unit cell parameter of the $\mathrm{RE}^{3+}$ : $\beta-\mathrm{PbF}_{2}$ nanocrystals of the glass-ceramic is always smaller than that of the ceramic as shown in Figure 4 and Table 3. For GCGd20, the difference is $0.059 \AA$ (Table 3), which represent approximately $1 \%$ or the unit cell parameter value. We propose that this difference is due to a pressure effect exerted by the glassy oxide matrix of the glass-ceramic on the $\mathrm{RE}^{3+}: \beta-\mathrm{PbF}_{2}$ nanocrystals.

Two hypotheses may be set out to account for this constrain.

At first, it may come from a difference in the thermal expansion coefficient between the $\mathrm{RE}^{3+}: \beta-\mathrm{PbF}_{2}$ nanocrystals that form under annealing of the parent glass for 10 hours at $390^{\circ} \mathrm{C}$ and the remaining glassy matrix.

The thermal expansion coefficient $\alpha$ of pure lead fluoride is typically $50 \times 10^{-6} \mathrm{~K}^{-1}$ at $400^{\circ} \mathrm{C}$ [28]. One can assume that the $\mathrm{RE}^{3+}: \beta-\mathrm{PbF}_{2}$ nanocrystals have a similar $\alpha$ value. The thermal expansion coefficient of the remaining germanate glass is unknown. However, several similar glasses have been investigated in the literature. Mixed-alkali germanate glasses have $\alpha$ values of $10-15$ $\times 10^{-6} \mathrm{~K}^{-1}$ at $300^{\circ} \mathrm{C}$ [29] and mixed silicate-germanate glasses have $\alpha$ values of typically $10 \times 10^{-6} \mathrm{~K}^{-1}$ between 293 and $573 \mathrm{~K}$ [30]. It is therefore reasonable to assume that the $\mathrm{RE}^{3+}: \beta-\mathrm{PbF}_{2}$ nanocrystals have higher thermal expansion coefficients than the remaining glassy matrix. The formation of the $\mathrm{RE}^{3+}: \beta-\mathrm{PbF}_{2}$ nanocrystals begins when the parent glass reach $390^{\circ} \mathrm{C}$, and is ended after a 10 hours heat treatment. Therefore these nanocrystals cannot be constrained upon cooling, since they shrink more than the remaining glassy matrix.

We are let with the second hypothesis which considers that the $\mathrm{RE}^{3+}: \beta-\mathrm{PbF}_{2}$ nanocrystals are constrained by the glassy matrix as soon as they form and grow upon annealing at $390^{\circ} \mathrm{C}$. It must be recalled that, for a given heat treatment, the devitrification rate of the GRE10x glass increases with $\mathrm{y}$. For GRE5, only $\sim 25 \%$ of the $\mathrm{RE}^{3+}$ : $\beta-\mathrm{PbF}_{2}$ nanocrystals are formed while $100 \%$ are formed upon the same annealing of GRE20 (Section 4.1). The higher is the nanocrystals content of the GCRE10x, the stronger will be the pressure exerted by the glassy matrix which cannot accommodate a large number of $\mathrm{RE}^{3+}: \beta$ $\mathrm{PbF}_{2}$ nanocrystals. Furthermore, the fluorine content of glass decreases when the lead fluoride crystallizes amplifying the constraint applied on nanocrystallites. Indeed, the pure oxide glass exhibits a more rigid network than the oxyfluoride one. This explain why the difference between the unit cell parameters $a$ of the ceramic and the glass ceramic, for a given $\mathrm{REF}_{3}$ content $(\mathrm{y}=10 \mathrm{x})$, increases with this content (Figure 4).

According to Table 3, the difference between the unit cell parameter of the glass ceramic and ceramic can reach $1 \%$, for GCGd20 compared to CGd20. For $\alpha-\mathrm{PbF}_{2}$, such shrinkage would correspond to an applied pressure of 1.6 GPa [31]. For the $20 \% \mathrm{Gd}^{3+} \beta-\mathrm{PbF}_{2}$ nanocrystals in the GCGd20 glass ceramic, the applied pressure is probably very similar.

\subsection{Unit Cell Parameter of the $\mathrm{Eu}^{3+}: \boldsymbol{\beta}-\mathrm{PbF}_{2}$ Nanoparticles Extracted from the GCEu20 Glass-Ceramic}

As indicated in Section 3.4, EDX microanalysis was performed on the nanocrystallites extracted from the GCEu20 glass-ceramic. It gives: Pb: 24.9\%, Eu: 5.6\%, F: $69.5 \%$, in atomic $\%$. No oxygen was detected, confirming that the glassy oxide matrix has been completely re- 
moved by the hydrofluoric acid treatment. Theoretically, considering the total precipitation of the $\mathrm{Eu}^{3+}: \beta-\mathrm{PbF}_{2}$ phase in the GCEu20 glass-ceramic and full segregation of europium ions into the lead fluoride, the $\mathrm{Eu}: \beta-\mathrm{PbF}_{2}$ nanocrystallites formula should be $\mathrm{Pb}_{10} \mathrm{Eu}_{2} \mathrm{~F}_{26}$, e.g. $\mathrm{Pb}$ : 26.3\%, Eu: 5.3\%, F: $68.4 \%$ (in atoms). This agrees rather well with the experimental determination given above.

It appears that the Bragg peaks of nanocrystallites extracted from the GCEu20 glass-ceramic, indicated by arrows in Figure 5(a), are exactly at the same positions than in the GCEu20 sample (Figure 5(d)), and shifted from those of the $\mathrm{CEu} 20 \mathrm{Eu}^{3+}: \beta-\mathrm{PbF}_{2}$ ceramic (Figure 5(c)). It means that the unit-cell parameter of the extracted nanocrystallites remains unchanged during the extraction process. The nanocrystallites remain constrained at room temperature even when the glassy matrix is removed.

After annealing of the extracted nanocrystallites for 3 hours at $400^{\circ} \mathrm{C}$, the Bragg diffraction peaks (Figure 5(b)) have a composite structure and can be fitted as a sum of three lorentzian peaks. For example, this is demonstrated in Figure 7 for the $\beta-\mathrm{PbF}_{2}$ (311) peak region around $2 \theta=$ $60^{\circ}$ (cobalt anode). The A peak is due to undoped $\beta-\mathrm{PbF}_{2}$ which was formed by transformation, under annealing, of the $\alpha-\mathrm{PbF}_{2}$ resulting from the chemical attack of the glassy matrix. The $\mathrm{C}$ peak is identical to the one of the $\mathrm{Eu}^{3+}: \beta-\mathrm{PbF}_{2}$ nanocrystallites of the GCEu20 glass ceramic and $\mathrm{B}$ identical to the diffraction peak of the $\mathrm{Eu}^{3+}$ : $\beta-\mathrm{PbF}_{2}$ ceramic $\mathrm{CEu} 20$. Thus, by this annealing treatment, the constrained metastable nanocrystallites extracted from the GCEu 20 glass-ceramics have been partly converted to relaxed $\mathrm{Eu}^{3+}: \beta-\mathrm{PbF}_{2}$ of the same composition. Assuming that the proportion of the $\mathrm{B}$ and $\mathrm{C}$ species are proportional to their peak areas, approximately $77 \%$ of the constrained nanocrystallites have been converted into regular $\mathrm{Eu}^{3+}: \beta-\mathrm{PbF}_{2}$ under such heat treatment. The $\mathrm{B}$ and $\mathrm{C}$ peak are broader than the $\mathrm{A}$ one. This is due to a smaller size of the constrained and relaxed nanocrystallites compared to that of the $\beta-\mathrm{PbF}_{2}$ resulting from the transformation of $\alpha-\mathrm{PbF}_{2}$.

Increasing the annealing duration at $400^{\circ} \mathrm{C}$ to 6 and 12 hours leads to a slight increase of the conversion rate of the constrained nanocrystallites but they do not disappear. This indicates that the activation energy barrier which separates the regular $\mathrm{Eu}^{3+}: \beta-\mathrm{PbF}_{2}$ particles, similar to the CEu20 ceramic, and the constrained ones, as it was in the glass ceramic, is rather high. For a 12 hour annealing, one notice a slight shift of the A peak towards larger diffraction angles, indicating that some europium is diffuseing from the doped nanoparticles to the pure $\beta-\mathrm{PbF}_{2}$ particles. Annealing of the constrained metastable nanocrystallites to $500^{\circ} \mathrm{C}$ for 3 hours completely relax the strains and only one diffraction peak, lying between the A and B one shown in Figure 7, is observed. This indicates that the undoped $\beta-\mathrm{PbF}_{2}$ crystals have reacted with the doped particles to give $\beta-\mathrm{PbF}_{2}$ with an intermediate doping rate, whose experimental $a$ parameter is equal to $\sim 5.93 \AA$ Á. Since the composition of the original glass is $40 \mathrm{PbO}$ for $10 \mathrm{Eu}^{3+}: \beta-\mathrm{PbF}_{2}$, the composition of the averaged ceramic is expected to correspond to $\mathrm{CEu} 4$ ceramic, whose unit cell $a$ parameter, equal to $5.933 \AA$ (Figure 3), is in good agreement with the experimental one.

\section{Conclusions}

Annealing of the glasses with composition $50 \mathrm{GeO}_{2-}$ $40 \mathrm{PbO}-10 \mathrm{PbF}_{2}-\mathrm{xREF}_{3}, \mathrm{RE}=\mathrm{Eu}, \mathrm{Gd}$, lead to the precipitation of $\mathrm{RE}^{3+}: \beta-\mathrm{PbF}_{2}$ nanocrystallites embedded in a $\left(50 \mathrm{GeO}_{2}-40 \mathrm{PbO}\right)$ glassy oxide matrix. Evolution of the crystallization temperature as function of the doping rate, crystallization rate $R$ and nanocrystallites size show that the Rare Earth ions have a strong nucleating effect for promoting the formation of $\mathrm{RE}^{3+}: \beta-\mathrm{PbF}_{2}$ nanocrystals from the lead fluoro-germanate glass. The nucleating effect is slightly stronger for $\mathrm{Eu}^{3+}$ than for $\mathrm{Gd}^{3+}$. This is related to the larger size of the europium ion, and to a higher stability of the $\mathrm{Eu}^{3+}: \beta-\mathrm{PbF}_{2}$ solid solution.

The unit cell parameter of the fluorite type $\mathrm{RE}^{3+}: \beta-\mathrm{PbF}_{2}$ solid solution decreases when the Rare Earth content increases and, for a given RE content, is always smaller for $\mathrm{Gd}$ than for Eu. This is quantitatively explained by the replacement of $\mathrm{Pb}^{2+}$ ions by smaller $\mathrm{RE}^{3+}$ cations, with simultaneous incorporation of interstitial $\mathrm{F}^{-}$ions in the lattice.

The $\mathrm{RE}^{3+}: \beta-\mathrm{PbF}_{2}$ nanocrystallites in the GCRE10x glass ceramics have always smaller unit parameters than the ceramics CREy of the same Rare Earth content. The highest difference observed can reach $1 \%$ for GCGd20, compared to CGd20. This is explained by considering that the glassy matrix exert a high pressure on the nanocrystallites formed under annealing. In the above-mentioned case, this pressure is evaluated to be about 1.6 GPa. The nanocrystallites of the glass-ceramics remain constrained at room temperature, even when the glassy oxide matrix is removed by chemical attack. They return partially to relaxed nanocrystals, with the same unit cell parameter than the ceramic of the same composition, under annealing for several hours at $400^{\circ} \mathrm{C}$. Heating at $500^{\circ} \mathrm{C}$ is required to achieve total conversion to unstrained ceramic.

\section{Acknowledgements}

The authors thank Mrs Akiko Suganuma for her help in the preparation of several samples used in this study.

\section{REFERENCES}

[1] G. Müller and N. Neuroth, "Glass-Ceramic-A New La- 
ser Host Material," Journal of Applied Physics, Vol. 44, No. 5, 1973, pp. 2315-2318. doi:10.1063/1.1662556

[2] P. A. Tick, N. F. Borrelli, L. K. Cornelius and M. A. Newhouse, "Transparent Glass-Ceramics for $1300 \mathrm{~nm}$ Amplifier Applications," Journal of Applied Physics, Vol. 78, No. 11, 1995, pp. 6367- 6374. doi:10.1063/1.360518

[3] M. C. Gonçalves, L. F. Santos and R. M. Almeida "Rareearth-Doped Transparent Glass-Ceramics," Comptes Rendus Chimie, Vol. 5, No. 12, 2002, pp. 845-854. doi:10.1016/S1631-0748(02)01457-1

[4] M. Mortier, "Between Glass and Crystal: Glass-Ceramics, a New Way for Optical Materials," Philosophical Magazine Part B, Vol. 82, No. 6, 2002, pp. 745-753. doi:10.1080/13642810208224364

[5] M. Mortier and D. Vivien, "Ceramic and Glass-Ceramic lasers," Annales de Chimie-Science des Matériaux, Vol. 28, No. 6, 2003, pp. 21-33. doi:10.1016/j.anncsm.2003.09.003

[6] V. Lavin, F. Lahoz, I. R. Martin and U. R. RodriguezMendoza, "Optical Properties of the Rare-Earth Ions in Transparent Oxyfluoride Glass-Ceramics" In: R. Balda, Ed., Photonic Glasses, Research Signpost, Kerala, 2006, pp. 115-149.

[7] M. Mortier and G. Dantelle, "Oxyfluoride Transparent Glass-Ceramics," In: A. Tressaud, Ed., Functionalized Inorganic Fluorides, Willey, New York, 2010, pp. 273 306.

[8] G. Dantelle, M. Mortier, D. Vivien and G. Patriarche, "Nucleation Efficiency of Erbium and Ytterbium Fluorides in Transparent Oxyfluoride Glass-Ceramics," Journal of Materials Research, Vol. 20, No. 2, 2005, pp. 472481. doi:10.1557/JMR.2005.0051

[9] G. Dantelle, M. Mortier, Ph. Goldner and D. Vivien, "EPR and Optical Study of $\mathrm{Yb}^{3+}$-Doped $\beta-\mathrm{PbF}_{2}$ Single Crystals and Nanocrystals of Glass-Ceramics," Journal of Physics: Condensed Matter, Vol. 18, No. 34, 2006, pp. 7905-7922. doi:10.1088/0953-8984/18/34/005

[10] G. Dantelle, M. Mortier and D. Vivien, "EPR and Optical Studies of Erbium-Doped $\beta-\mathrm{PbF}_{2}$ Single-Crystals and Nano-Crystals in Transparent Glass-Ceramics," Physical Chemistry Chemical Physics, Vol. 9, No. 41, 2007, pp. 5591-5598. doi:10.1039/B706735F

[11] C. Bensalem, M. Mortier, D. Vivien and M. Diaf, "Thermal and Optical Investigation of $\mathrm{EuF}_{3}$-Doped Lead Fluoroger-Manate Glasses," Journal of Non-Crystalline Solids, Vol. 356, No. 1, 2010, pp. 56-64. doi:10.1016/j.jnoncrysol.2009.09.023

[12] C. Bensalem, M. Mortier, D. Vivien and M. Diaf, "Optical Investigation of $\mathrm{Eu}^{3+}: \mathrm{PbF}_{2}$ Ceramics and Transparent Glass-Ceramics," Optical Materials, Vol. 33, No. 6, 2011, pp. 791-798. doi:10.1016/j.optmat.2010.12.024

[13] R. T. Wegh, H. Donker, K. D. Oskam and A. Meijerink "Visible Quantum Cutting in $\mathrm{LiGdF}_{4}: \mathrm{Eu}^{3+}$ through Downconversion," Science, Vol. 283, No. 5402, 1999, pp. 663666. doi:10.1126/science. 283.5402 .663

[14] C. R. Ronda, "Phosphors for Lamps and Displays: An Applicational View," Journal of Alloys and Compounds, Vol. 225, No. 1-2, 1995, pp. 534-538. doi:10.1016/0925-8388(94)07065-2

[15] D. Zhao, X. Qiao, X. Fan and M. Wang, "Local Vibration around Rare-Earth Ions in $\mathrm{SiO}_{2}-\mathrm{PbF}_{2}$ Glass and Glass-CeRamics Using Eu ${ }^{3+}$ Probe," Physica B: Condensed Matter, Vol. 395, No. 1-2, 2007, pp. 10-15. doi:10.1016/j.physb.2006.12.007

[16] K. Driesen, V. K. Tikhomirov and C. Görller-Walrand, " $\mathrm{Eu}^{3+}$ as a Probe for Rare-Earth Dopant Site Structure in Nano-Glass-Ceramics," Journal of Applied Physics, Vol. 102, No. 2, 2007, Article ID: 024312. doi:10.1063/1.2759195

[17] L. A. Bueno, A. S. Gouveia-Neto, E. B. da Costa, Y. Messaddeq and S. J. L. Ribeiro, "Structural and SpectroScopic Study of Oxyfluoride Glasses and Glass-Ceramics Using Europium Ion as a Structural Probe," Journal of Physics: Condensed Matter, Vol. 20, No. 14, 2008, Article ID: 145201 . doi:10.1088/0953-8984/20/14/145201

[18] M. Mortier and G. Patriarche, "Oxide Glass Used as Inorganic Template for Fluorescent Fluoride Nanoparticles Synthesis," Optical Materials, Vol. 28, No. 12, 2006, pp. 1401-1404. doi:10.1016/j.optmat.2005.07.008

[19] P. Caussin, J. Nusinovici and D. W. Beard, "Using Digitized X-Ray Powder Diffraction Scans as Input for New PC-AT Search/Match Program," Advanced X-ray Analysis, Vol. 31, 1988, pp. 423-430.

[20] P. Caussin, J. Nusinovici and D. W. Beard, "Specific Data Handling Techniques and New Enhancements in Search/Match Program," Advanced X-Ray Analysis, Vol. 32, 1989, pp. 531-538.

[21] J. Laugier, B. Bochu, "Laboratoire des Matériaux et du Génie Physique," 1999. http://www.lmgp.grenoble-inp.fr/

[22] M. Mortier and G. Patriarche, "Structural characterisation of Transparent Oxyfluoride Glass-Ceramics,"Journal of Materials Science, Vol. 35, No. 19, 2000, pp. 4849-4856. doi:10.1023/A:1005661315593

[23] G. Dantelle, M. Mortier, G. Patriarche and D. Vivien, "Er ${ }^{3+}$-Doped $\mathrm{PbF}_{2}$ : Comparison between Nanocrystals in Glass-Ceramics and Bulk Single Crystals" Journal of Solid State Chemistry, Vol. 179, No. 7, 2006, pp. 19952003. doi:10.1016/j.jssc.2006.03.038

[24] A. Dib, S. Aléonard and M. Th. Roux, "Synthèse et Caractéristiques Cristallographiques des Phases Solides de Type Fluorine des Systèmes $\mathrm{PbF}_{2}-\mathrm{LnF}_{3}$,'Journal of Solid State Chemistry, Vol. 52, No. 3, 1984, pp. 292-301. doi:10.1016/0022-4596(84)90012-4

[25] G. Dantelle, M. Mortier, D. Vivien and G. Patriarche "Effect of $\mathrm{CeF}_{3}$ Addition on the Nucleation and Up- Conversion Luminescence in Transparent Oxyfluoride GlassCeramics," Chemistry Materials, Vol. 17, No. 8, 2005, pp. 2216-2222. doi:10.1021/cm047821d

[26] J. E. Huheey, E. A. Keiter and R. Keiter, "Inorganic Chemistry, Principle of Structure and Reactivity," Harper Collins College Publishers, New York, 1993.

[27] S. N. Achary, A. K. Tyagi, P. Balog and J. Köhler, "High-Pressure and High-Temperature Studies on Fluorite-Type $\mathrm{Pb}_{1-\mathrm{x}} \mathrm{Nd}_{\mathrm{x}} \mathrm{F}_{2+\mathrm{x}}(\mathrm{x}=0.15$ and 0.25$)$," Journal of Alloys and Compounds, Vol. 417, No. 1-2, 2006, pp. 250 
253. doi:10.1016/i.jallcom.2005.08.069

[28] T. S. Aurora, D. O. Pederson and S. M. Day, "Thermal-Expansion and Index-of-Refraction Variation in Lead Fluoride between 300 and $850 \mathrm{~K}$," Physical Review B, Vol. 41, No. 14, 1990, pp. 9647-9649. doi:10.1103/PhysRevB.41.9647

[29] J. E. Shelby, "Thermal Expansion of Mixed-Alkali GermaNate Glasses" Journal of Applied Physics, Vol. 46, No. 1, 1975, pp. 193-196. doi:10.1063/1.321318

[30] H. Darwish, S. N. Salama and S. M. Salman, "Contribu- tion of Germanium Dioxide to the Thermal Expansion Characteristics of Some Borosilicate Glasses and Their Corresponding Glass-Ceramics" Thermochimica Acta, Vol. 374, No. 2, 2001, pp. 129-135. doi:10.1016/S0040-6031(01)00481-6

[31] L. Ehm, K. Knorr, F. Mädler, H. Voigtländer, E. Busetto, A. Cassetta, A. Lausi and B. Winkler, "High-Pressure X-Ray Diffraction Study on $\alpha-\mathrm{PbF}_{2}$," Journal of Physics and Chemistry of Solids, Vol. 64, No. 6, 2003, pp. 919925. doi:10.1016/S0022-3697(02)00437-7 